six, from whom Billroth had extirpated the left half of the larynx for carcinoma. The case apparently was explained by the discovery of an anastomosis between the external branch of the superior laryngeal and the superior cardiac branch of the sympathetic. He assumes that this anastomotic branch may contain cardiac depressant fibres, possibly from its connection with the superior laryngeal norve. However, the practical point for the surgeon is that the danger exists; and since the nerve is more frequent on the left than the right side, left-sided operations are to be considered more dangerous. For a detailed anatomical description the reader is referred to the original article ${ }^{12}$ or a good résumé.

THE RESULTS OF REMOVAL, OF THL BRLAST.

Terrillon, ${ }^{18}$ has arrived at the following conclusions as a result of partial or total removal of the breast in one hundred patients, in the treatment of tumors of various kinds:

The gravity of the operation is insiguificant; recurrence seems to be the rule when the axillary glands are involved in the disease; when mammary tumors are malignant, or of a mixed character, the entire gland and involved lymphatic glands should bo removed if recurrence takes place. 'The operation may be repeated once or several times, especially if primary union of the skin can bo secured; by this means the condition of the patient is ameliorated, the drain attending ulceration is obviated, and the unfavorable course of the disease seems to be retarded.

\section{TREATMENT OF TRAUMATIC PNEUMOTHORAX.}

Witzel ${ }^{14}$ successfully relieved a case of this nature, which forms such a dangerous complication in wounds of the thorax by impeding respiration and pressure on heart and large blood-vessels, by placing a catheter in the upper angle of the wound, then suturing the opening till air-tight; then filling the pleural cavity with warm boric acid solution, which gradually displaced the air, which escaped through the catheter. The liquid then was removed by siphoning it out through the catheter. After this procedure respiration became quiet and regular, and percussion and ascultation showed normal conditions.

REMOVAL OF THE APEX OF THE LUNG FOR TUBERCULOSIS.

Dr. 'Tuffier, 16 in a case of early tuberculous disease of the apex of the right lung, resorted to an operation. A simple incision was made through the second intercostal space anteriorly ; the parietal pleura was divided, which induced a kind of sub-pleural pneumothorax; the upex of the lung became reduced in bulk sufficiently to be easily drawn through the wound; it was then cut away by the ecraseur, and the stump sutured to the intercostal incision to prevent retraction of the lung. The case progressed very favorably after the operation.

(To be continued.)

True King of the Belgians has consented to be $\mathrm{Pa}$ tron of the International Congress of Gynecology and Obstetrics, which will meet this year at Brussels.

1: Schmidt Jalır, f. gesamt. Med., 1891, No. 3, p. 396.

is Bulletin Géu. do Thorap., May 15, 1891 ; Medionl Newe, July 11, 1891 .

is Contbl. f. Chir. 1891, No. 28

1" Gazelto hold. do Sol. Med.; Medical Nows, Soptember, 1891.

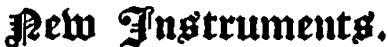

\section{AN IMPROVED APPARATUS FOR ESTIMATING UREA.}

IIY H. F. ADAMI, M.D., IHOKNIX, ARIZONA.

Tue convenient hypobromite process has called out numerous devices to make the quantitative analysis of urine for urea at once handy and rapid.

'Those of Marshall, ${ }^{1}$ Green, Doremus ${ }^{2}$ and Squibb ${ }^{8}$ are perhaps the best.

'The modification figured below, possesses, I believe, the following advantages:

(1) It is inexpensive. It is easily made from ordinary glass tubing with a common alcohol lamp.

(2) It reduces the cost of analysis, requiring only about one quarter of the amount of caustic soda and bromine needed by others.

(3) It is neater to use and easier to clean. Neater to use, because it can be filled and operated without soiling the fingers, and because of the small amount of caustic solution to overflow; and easier to clean, because the apparatus is of uniform calibre, and rinses easily.

(4) It is of superior accuracy : first, becuuse of the small calibres of the urine-pipette and of the nitrogenreceiver, thus giving very close readings; second, because of the adjustment of the urine-pipette, and of the absence of any waste or error in adding the urine, as often happens with the usuul pipettes; third, becuuse of the long column of hypobromite solution, favoring a rapid and complete decomposition of the urea as the urine rises.

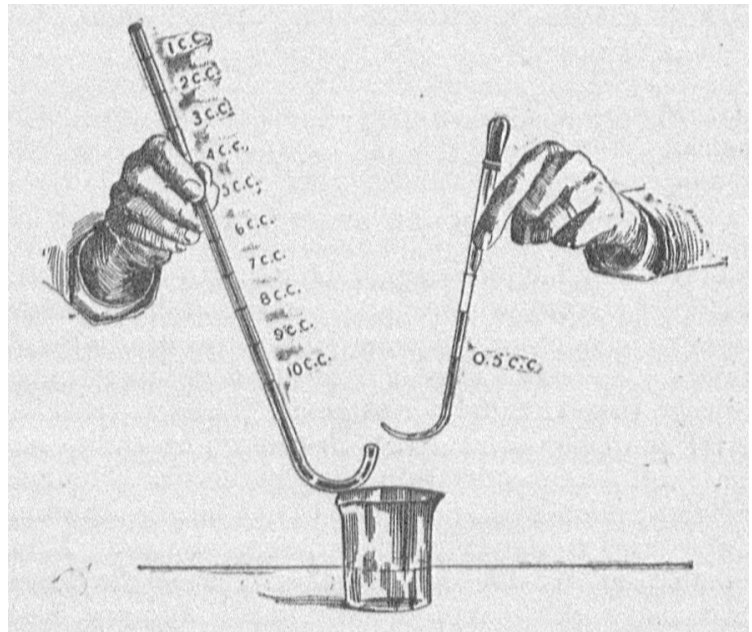

The ureometer is made from glass tubing having a little more than a quarter-inch bore. It is fifteen inches long, closed at one end, and curved at the other for about three inches, with a radins of one inch. It holds, filled, about seventeen cubic centimetres, and is graduated from the closed end in cubic centimetres. It is best filled with the sodium hypo. bromite solution by means of a long pipette, with a small delivery, which easily takes the solution from a bottle and prevents any spilling.

The urine is added by a pipette made of very small glass tubing curved to the same radius as the large tube. This curved pipette is long enough to contain

1 Tyson's Prat. Exam. Urine, 7th Edition, I. 166.

3 Ephemeris, January, 1884. 
something more than one-half cubic centimetre, and is a large number of observations made to show that regraduated to that amount. It is attached by a short lation in the dissecting-room, and I think he found that piece of rubber tubing to an ordinary medicine drop- the nerve generally went behind the artery, although per. 'This attachment allows the analyst to take up a that is not constant. It seems to me to avoid the relittle more than one-half cubic centinetre of urine, current nerve you need to keep well away from the and then to adjust exactly to that quantity without trachea and osophagus, because unless the tumor is touching the bulb.

The pipette thus loaded is introduced into the tubo full of hypobromite solution, exactly as a male catheter is passed. The pipette should have a very small delivery, allowing a very slow discharge of the urine. 'The overflow of the caustic solution is caught in a beaker. 'The tube may be sunk in a vessel of water to the level of the remaining liquid, in order to correct the pressure, before reading the amount of nitrogen.

The solutions used, and the calculation of the result, are according to the usual standards. Each cubic centimetre of nitrogen is nearly the product of 0.00282 grammes of urea; or, each $1 \%$ of urea, in the 0.5 c. c. of urine used, gives 1.77 c.c. of nitrogen. From these figures it is easy to graduate the tube so as to read the percentage of urea without calculation.

\section{Reparti of Societieg.}

\section{BOSTON SOCIETY FOR MEDICAL IMPROVE- MEN'T.}

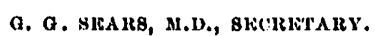
very low down indeed the nerva is there between the two. I have had quite gratifying results in the treatment of cystic tumors by drainage, and one case in which it was necessary to insert a tube into the trachea through a very large malignant growth, perhaps one of the most diflicult operations. In the cystic variety, Dr. Warren may remember the old man who came a year ago with an enormous thyroid tumor. 'This I succeeded in curing by drainage. I think, if we can find that it is possible to remove thyroid tumors with safety and without the serious after-eflects, that we shall have opened a very great and interesting field in surgery, which thus far has beou very littlo explored in this vicinity.

Dr. Mixter: I was fortunate enough to see a very considerable number of these cases in Billrotl's ward in Vienna; and a very large number were operated on, some being what were supposed to be total extirpations, but others partial, and there were also a largo number treated by the injection of iodine and other substances, 80 that I had a very considerable number of cases to watch in ull the different stages, and also had the privilege of making sectious of all the growths removed, and I have now specimens from all the thyroid tumors I believe that were removed for a considerable number of years in Billroth's clinic. There are

Rkgurar Meeting, Monday, February 8, 1892, the President Dr. Frederick I. KNJGirt in the chair.

DR. J. C. W ARRkN read a paper on

THE OPKRATIVE TREATMENT OF GOITRL."

Dr. Warren: Cretinism is etiologically and pathologically a different disease. Superficially the two diseases resemble one another very much. There is in both a disturbed look about the face, feeble mental condition, imperfect action of the organs of sense, etc. Here the resemblance ceases. In the case of myxadema the distortion is due to the condition of the tissues. In cretinism the distortion is due to the shape of the bones. The widening of the face, of the eyes, peculiar distortion of the head, are characteristic of cretivism, and due probably to the condition of the skeleton rather than of the soft tissues. The connective-tissue is the one chiefly affected in the myxodema cases. The condition of mind in the myxoedema cases is not necessarily as bad as one might suppose. 'They are slow of thought, but they appear to have more or less intellect and do not seem to lose their intelligence. Their movements are slow.

Dr. Richardson: 'This paper has been very interesting to me. I am sorry to say that $I$ have no experience in the entire removal of thyroid tumors. Case I, was under my observation some weeks in the summer, and I did not operate because I did not think that the tumor was large enough to cause any inconvenience except from its unsightly appearance. I was very sorry afterwards that I did not operate when I learned the nature of it. It always seemed to me a very in formidable operation. I dare say it is not so difficult as it seems. The position of the inferior thyroides and their relation with the recurrent nerve makes it very important to avoid that nerve. Dr. Dwight had a number of points that come up in the paper, and the lirst is the position of the thyroid tumor in its relation to the trachea and the ocsophagus. Generally the compression Dr. Warren says is from the side, but I have seen, in at least two cases that Billroth removed, where the trachea seemed to be encircled by the enlarged thyroid, in other words, where, instead of passing across, the tumor extended directly round the trachea and the ocsophagus, completely encircling it, and of course in that position the operation was very much more difficult, the trachea and the osophagus being completely separated. In those cases I think the recurrent laryngeal nerve was generally exposed and sought for and found before the operation was carried to its completion. The injection of iodine I saw in a good many cases and with very varying results. In some cases the tumor was rapidly diminished, and in other cases, as a rule, a swelling following the injection, and then a diminution in size which carried it down to a con. siderable point below where it stood at the time of the injection. In other cases, after this inflammatory process had apparently subsided, the tumor would grow much more rapidly, and in these cases it was invariably removed; and in a large number of these cases I bolieve tho growth was found to be sarcomatous. In the ordinary cystic tumor it was very generully quite successful, but I have one tumor that was removed, in which this injection had been male a large number of times and at different points. You can see the cicatrices and slurinking following, and there is one point showing the inflammatory process following the injection.

'The paralysis of the recurrent laryngeal has been spoken of, and that is a very important thing to avoid. In some of these cases it was rather startling to find that there was this paralysis, but in all these cases it was temporary. In some of the malignant cases these 